MATEC Web of Conferences 3, 01048 (2013)

DOI: $10.1051 /$ matecconf/20130301048

(C) Owned by the authors, published by EDP Sciences, 2013

\title{
Thermodynamic excess properties of 3,5- and 2,6-dimethylpyridine with cyclohexane measurement and prediction
}

\author{
H. Ben-makhlouf-Hakem ${ }^{1}$, A. Ait-kaci ${ }^{1}$, and J. Jose ${ }^{2}$ \\ ${ }^{1}$ Laboratoire de thermodynamique des mélanges organiques, Faculté de chimie, USTHB, B.P 32, El-Alia 16111 Bab \\ Ezzouar, Algeria \\ ${ }^{2}$ Laboratoire de chimie analytique I, Université Claude Bernard (Lyon I), 43 Boulevard du 11 novembre 1918,Bât. \\ Raulin/2, 69622 Villeurbanne Cedex, France
}

\begin{abstract}
The vapour pressures of liquid $(3,5 ; 2,6)$-dimethylpyridine with cyclohexane mixtures were measured by a static method in the range of $283.15-353.15 \mathrm{~K}$. The pure components vapour pressures data and those of the mixtures were correlated with the Antoine equation. The molar excess Gibbs energies, calculated from the vapour-liquid equilibrium data compared satisfactorily with group contribution method (DISQUAC).
\end{abstract}

\section{Introduction}

Vapor -liquid equilibrium (VLE) data are essential for engineering design of separation processes and unit operations. It is useful for an extension of a few thermodynamical models commonly applied for designing petrochemical related processes. Such information can be obtained experimentally or adopted from generalized methods to calculate properties of multi-component mixtures. Most liquid systems of industrial interest deviate from ideal behavior. Usually, densities of vapor and liquid phases are important to give proper size in the process design of many separation equip

\section{Experimental}

The total vapor pressure measurements were carried out with a static method described elsewhere by BlondelTellouk et al. [1] Mixture compositions were prepared by mass and degassed by distillation as described previously by Blondel-Tellouk et al. [1]. The liquid phase was analyzed by chromatography (GLC).The pure components vapor pressures data and those of the mixtures were correlated with the Antoine equation. Vapour phase imperfection and variation of the Gibbs energy of the pure liquid components with pressure were accounted for in terms of the $2^{\text {nd }}$ molar virial coefficients and the molar volumes under saturation pressure.

$$
\begin{aligned}
& P=\sum_{i=1}^{2} \frac{x_{i} P_{i}^{0} \exp \left[g_{i}^{E}-\left(B_{i i}-V_{i}^{0}\right)\left(P-P_{i}^{0}\right)-2 P B_{12}\left(1-y_{i}\right)^{2}\right]}{R T} \\
& y_{i}=\frac{x_{i} P_{i}^{0}}{P} \exp \left[g_{i}^{E}-\left(B_{i i}-V_{i}^{0}\right)\left(P-P_{i}^{0}\right)-2 P B_{12}\left(1-y_{i}\right)^{2}\right] \\
& \left.B^{E}=B_{12}-\left(B_{11}+B_{12}\right) / 2 ; \quad P_{i}^{0}=P_{(x i=1}\right)
\end{aligned}
$$

Where $\mathrm{V}_{i}^{0}$ is the molar volume of the pure compound estimated with the Rackett equation using the literature data for acentric factor and critical properties [3] and $\mathrm{B}_{\mathrm{ii}}$ the $2^{\text {nd }}$ molar virial coefficients evaluated with Tsonopoulos method $[5,6]$.

The equilibrium pressure and composition data ( $\mathrm{P}-\mathrm{X}$ $\mathrm{Y})$ at different temperatures are plotted in figure 1 . 
3,5-lutidine(1)+cyclohexane

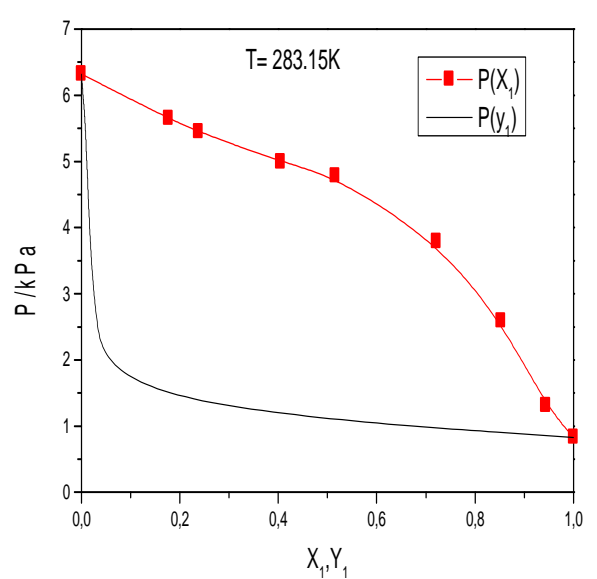

3,5-lutidine(1)+cyclohexane

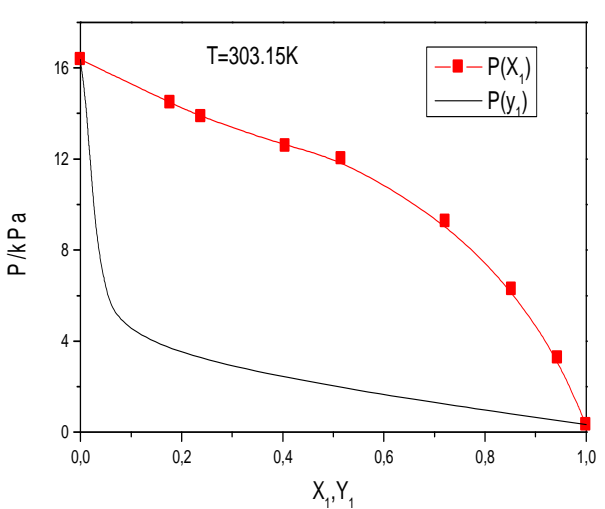

3,5-lutidine(1)+cyclohexane

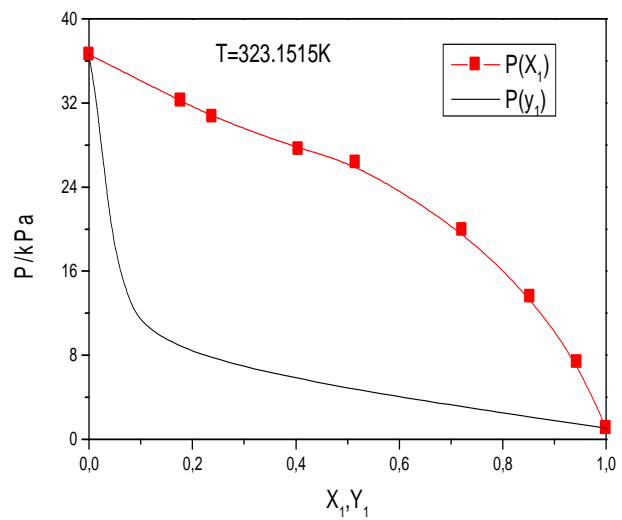

2,6-lutidine(1)+cyclohexane

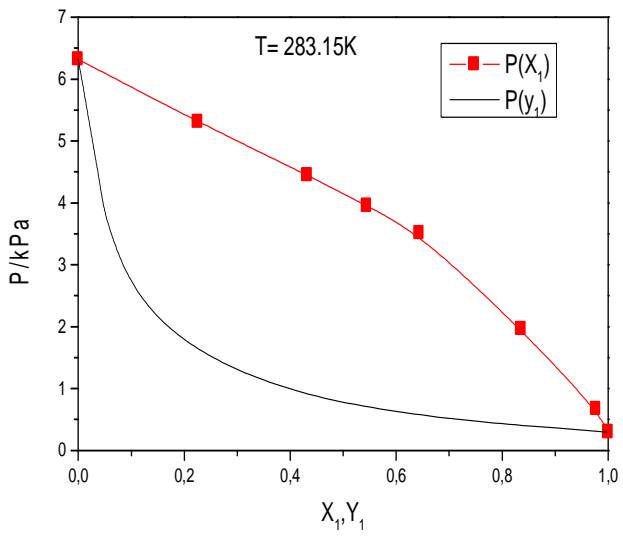

2,6-lutidine(1)+cyclohexane

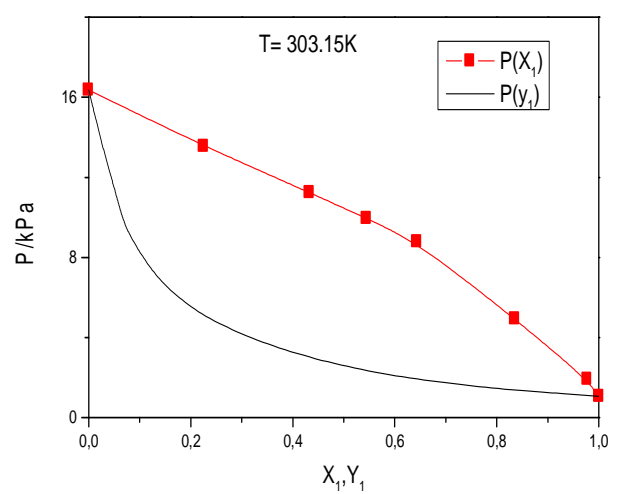

2,6-lutidine(1)+cyclohexane

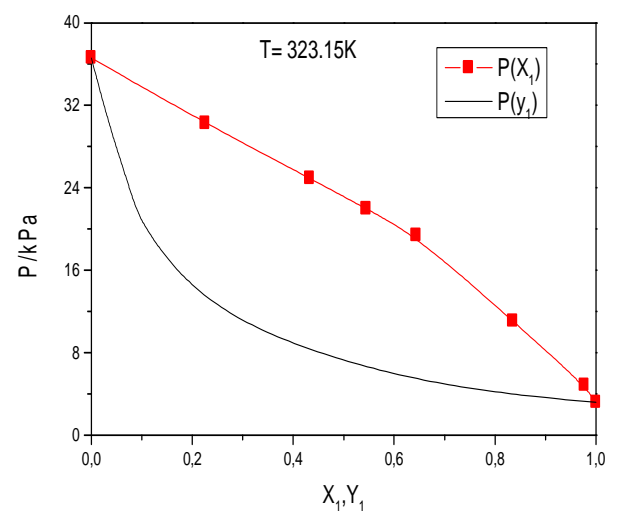

Figure 1. Isothermal vapor-liquid equilibrium of 3,5-lutidine or 2,6-lutidine with cyclohexane at $(283.15,303.15$ and $323.15 \mathrm{~K})$. 
The excess molar Gibbs energies $G^{\mathrm{E}}$ are calculated by Barker'smethod [2] using the Redlich-Kister equation.

\section{Modeling and results}

The thermodynamic excess functions of organic liquid mixtures depend on the chemical nature, the size and the shape of the constituent molecules.

Recently it has been suggested that additional contributions arise in systems containing molecules of anisotropic shape (orientational order) or of different degrees of internal motion (conformational effects) The interactional terms in the thermodynamic properties under consideration are given by the DISQUAC model (group contribution method) [6] as the sum of the dispersive (DIS) and the quasi-chemical (QUAC) contribution.

$G^{E}=G_{c o m b}^{E}+G^{E, D I S}+G^{E, Q U A C}$

The combinatorial term , $\mathrm{G}^{\mathrm{E}}{ }_{\text {comb }}$ is represented by FloryHuggins equation $[7,8]$.

The model DISQUAC reproduces quite accurately the experimental measurements $G^{E}$.

The figure 2 shows the position methyl groups effect on the excess function $\mathrm{G}^{\mathrm{E}}$.

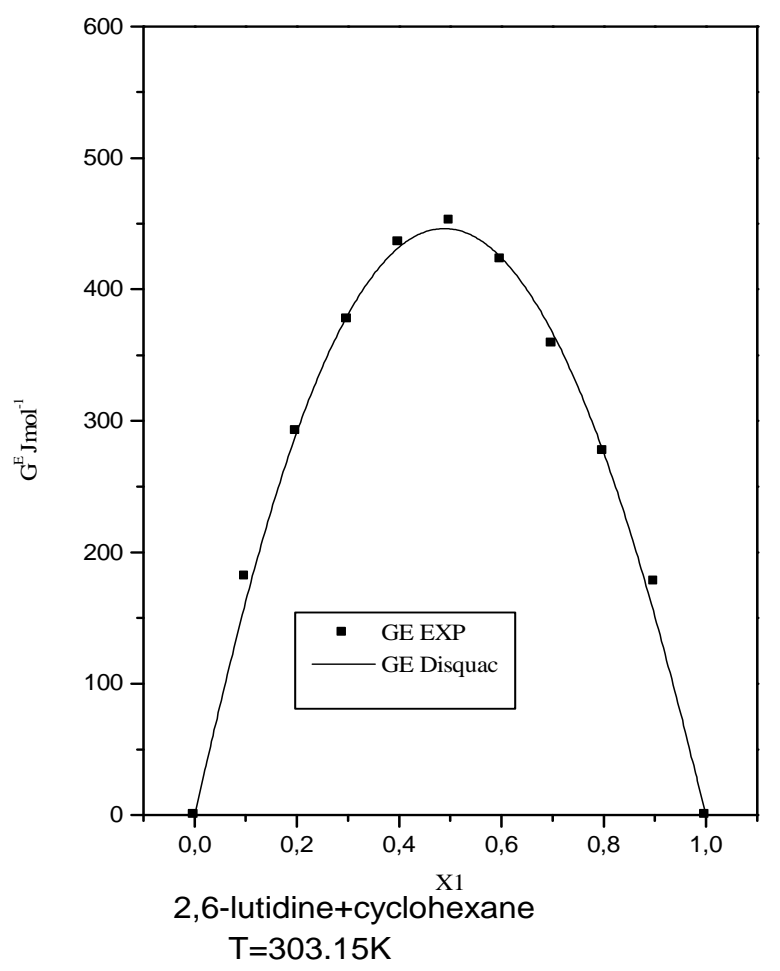

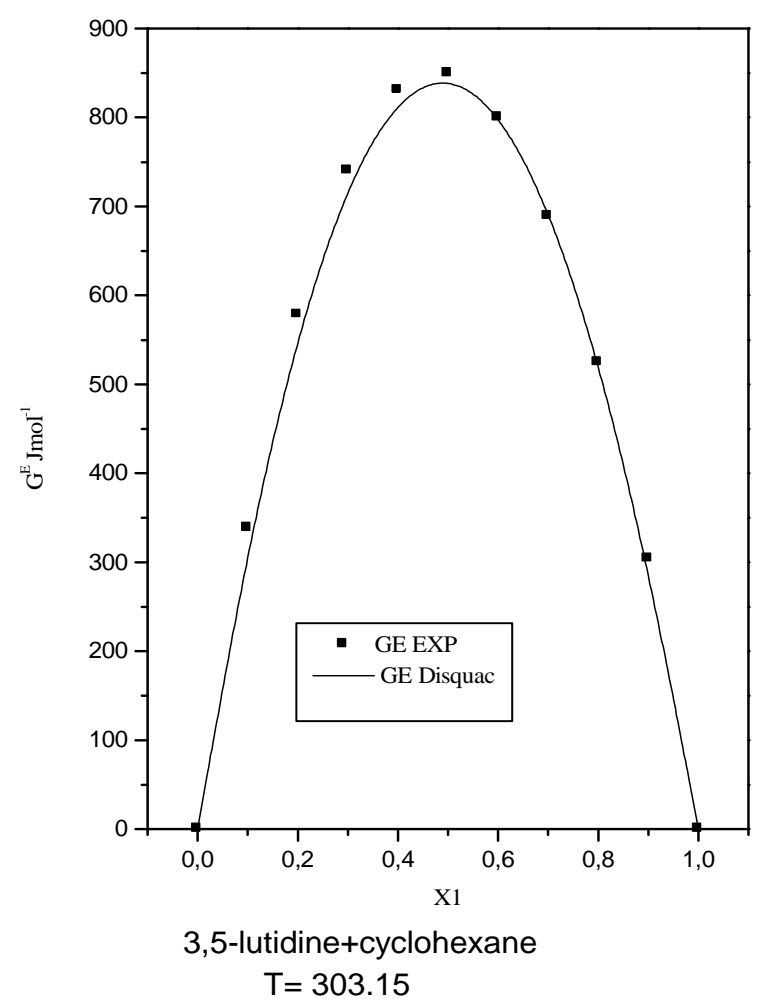

Figure 2. Comparison of theory with experiment for the molar excess Gibbs energy $G^{E}$ at $303.15 \mathrm{~K}$ of 2,6- or 3,5-lutidine (1) + cyclohexane (2) mixtures versus $\mathrm{x}_{1}$, the mole fraction of lutidine. Full lines, predicted values using DISQUAC model; points, experimental results ; $G^{E}(\cdot)$ ( this work).

\section{References}

1. A. Blondel-Tellouk, H. Loiseleur, A. Barreau, E. Behar, J. Jose, Fluid Phase Equilibria 110315 (1995)

2. J.A. Barker, Austr. J. Chem. 6207 (1953)

3. H.G. Rackett, J. Chem. Eng. Data 15514 (1970)

4. C. Tsonopoulos, AICHE J. 20263 (1974)

5. C. Tsonopoulos, J. AICHE 20827 (1975)

6. M.R. Tiné, H.V. Kehiaian, Fluid Phase Equilibria 32 211 (1987)

7. H.V. Kehiaian, J.-P.E. Grolier, G.C. Benson, J. Chim. Phys. 151031 (1978)

8. J.A. Gonzalez, I. Garcia de la Fuente, J.C. Casanova, A. Ait-Kaci, Fluid Phase Equilib. 11263 (1995) 